\title{
HEALTH LITERACY ASSESSMENT OF VIDZEME STATISTICAL REGION
}

Baiba Kondrica ${ }^{1}$, Mg.paed./ PhD cand., Ilze Ivanova², Dr.paed./ Professor and

${ }^{10}$ Tamara Grizane $^{3}$, Dr.oec./ Assistant Professor

1, 2, University of Latvia, 3 Turiba University

\begin{abstract}
Data on Health Literacy in the population of Latvia is limited. The aim of the study was to determine the Health Literacy impacting factors of inhabitants of Vidzeme Statistical region in Latvia (LV008). Respondent survey ( $n=383$ ), using a paper-and-pencil self-administered approach and telephone interviews, was conducted based the European Health Literacy Survey Questionnaire (HLS-EU-Q47). In order to ensure internal consistency and reliability, the authors used Cronbach's $a$ test $(a=0.965)$. The confirmatory factor analysis (CFA) allowed to determine that factor results differentiate between genders and there is a strong positive correlation $(r=0.945)$, that impacts results. Factors Access, Appraise and Apply explained each $30 \%$ of the variance, and factors Understand explained $31 \%$. HL index division by gender indicated that $47.4 \%$ of female respondents and $46.6 \%$ of male respondents have "limited health literacy" ("inadequate" + "problematic"). The largest age group among respondents are 18-39-year old where there is lower level of education and lower income. However, cases have been observed when respondents even with higher education have "limited health literacy," which indicates towards a need for further HL research in Latvia, because compared to $\mathrm{HL}$ of other member states, LV008 HL index is by $38.9 \%$ larger than the EU average (47.6 \%).
\end{abstract}

Key words: health literacy.

JEL code: I12; I13

\section{Introduction}

The European Health literacy research (HLS-EU) indicates that on average $47 \%$ respondents have encountered difficulties in health management (Sorensen, 2015). The limited health literacy is an actual health risk for the society ever more during the spread of COVID-19. Multiple EU member states are researching the knowledge, motivation, competencies of people to access information on topics concerning health, to understand that, to evaluate, and to use it in order to make conclusions and take appropriate decisions in everyday life concerning the healthcare, disease prevention, health improvements and life quality (ABS, 2009; Berkman et al., 2011; Altin, 2014; Connor, Mantwill, and Schulz, 2013; Guzys, Kenny, Dickson-Swift, 2015).

Health Literacy (HL) as a term was defined first in 1974 (Pelikan, 2014). Over the years multiple HL definitions have been proposed (Berkman et al, 2010; Freedman et al, 2009, Kickbusch, Nutbeam, 2008). However, the definition itself has been created by the National Library of Medicine, and that defines the $\mathrm{HL}$ as the level at which person can acquire, process and understand the basic information about the health and healthcare services, which is necessary to take responsible health related decisions "the knowledge, motivation and competences to access, understand, appraise and apply health information in order to make judgments and take decisions in everyday life concerning healthcare, disease prevention and health promotion to maintain or improve quality of life throughout the course of life" (Sorensen et al., 2012).

The essence of the HL definition is focused on the ability to search, find, acquire, understand, evaluate and use health information, in order to take based decisions about individual health condition and the health of society (Sorensen et al., 2012).

Researchers identified that high $\mathrm{HL}$ is linked to profound knowledge about the health, less frequent cases of sickness and reduced expenditures linked to sickness (Mancuso, 2008; Baker, 2006). However, low $\mathrm{HL}$ is equivalent to average knowledge about health issues and is linked to higher rates if sickness and increased health services are related with expenses (Scott et al, 2002; Kim, 2009; Rowlands, Protheroe, Price, Gann, Raf, 2014; Wallace, Perkhounkova, Bohr, Chung, 2016). However, there is a variety of other 
factors that are linked to $\mathrm{HL}$, linked to sex, education, occupation, income level i.e. demographical and socio-economic factors of respondents. (Solar, Iewin, 2010; Bodur, Filiz, Kalkan, 2017).

The OECD and the Government of Latvia have identified $\mathrm{HL}$ as a priority that ought to be developed. The research into $\mathrm{HL}$ is aimed at the role of patient satisfaction with the healthcare services, at the development of HL skills (Rasnaca, Vibane, Nikisins 2017; Onose et al., 2017; Silkane, Davidsone, Veliverronena, 2018). When assessing and comparing the HL situation in Latvia with that in other EU member states, it does not look bright (Heijmans at el., 2015).

Authors believe that $\mathrm{HL}$ and its factors have not attracted significant attention in the public space, and information about the health and health literacy is available in a limited amount. Consequently, the First Global Health Literacy Summit by the International Health Literacy Association (IHLA) has raised the need to affirm the importance of health literacy (IHLA, 2021).

Taking into account the lack of HL information basis in Latvia, which was indicated by the European Commission study (Heijmans at el., 2015), authors suggested the following aim: determination of factors affecting health literacy of the population of Vidzeme statistical region in Latvia. The research tasks: (1) to carry out analysis of scientific literature about health literacy survey HLS-Q (questionnaire), used methods in factor determination; (2) to carry out survey, to determine and evaluate factors limiting the $\mathrm{HL}$; (3) to determine the $\mathrm{HL}$ index divisions by gender, age, education, and gross income per month; (4) to compare the statistical sample of Vidzeme Statistical Region HL index with that of other EU member states.

The methods applied: descriptive method, Pearson's correlation, Chi-square test, KMO and BARLETT'S, Cronbach's Alpha, Manova and Mancova tests, Exploratory Factor Analysis and Principal Components Analysis.

\section{Materials and methods}

The Statistical region Vidzeme (LV 008) as a research region is one of six regions of Latvia (NUTS III) (Nomenclature of territorial units for statistics, small regions for specific diagnoses), where the number of population of working age (in the range of 18-64 years) population according to the Central Statistical Bureau (CSB), is 383 respondents, calculation of survey respondent size has been created proportionally 110868 (CSB, 2020). The calculated sample size is to LV 008 working age population. The survey was conducted from May 2020 till December 2021, while deployed with mixed technique, using a paper-andpencil self-administered approach (PAPI), and phone interviews.

HL was based on the HLS-EU-Q47 (Sorensen et al., 2013). The questionnaire consists of 47 items of which must be rated on 4-point Likert scales ( 1 = very difficult, 2 = difficult, $3=$ easy, and $4=$ very easy), which identifies 4 competences related to managing health information (access, understand, appraise, and apply information). This allows the calculation of a general HL index and index of each of the 4 competencies. The $\mathrm{HL}$ indices were standardized to unified metrics from 0 to 50 using the formula (HLS-EU Consortium, 2012):

$$
\text { Index }=(M-1) \times(50 / n))
$$

where

index - was the specific index calculated;

M - the mean of all participating items for each person;

1 - was the minimal possible value of the mean (leading to a minimum value of the index of 0 );

$\mathrm{n}$ - was the range of the mean;

50 - was the chosen maximum value of the new metric. 
The acquired HL index was grouped according to value in 4 groups: 0-25 - inadequate; $>25-33$ problematic; >33-42 - sufficient, and >42-50 - excellent HL, in order to evaluate the HL of respondents according to gender, age, education, and gross income per month (EUR) and to compare to other countries. To detect vulnerable groups, the "inadequate" and "problematic" levels were combined to a single level, called "limited health literacy" (0-33) (Sorensen, 2015).

In order to test the internal consistency, reliability test Cronbach's a was conducted. Correlation and regression analysis was performed. The results were considered at the level of significance $p<.05, p<.01$ and $\mathrm{p}<.001$.

\section{Research results and discussion}

During the study, analysis of 10 researches from 2015 to 2020 was conducted, including 17 countries (Austria, Bulgaria, Germany, Greece, Indonesia, Ireland, Japan, Kazakhstan, Korea, Malaysia, Myanmar, Netherlands, Norway, Poland, Spain, Taiwan and Vietnam). The research revealed that for basis for similar researches the European Health Literacy Survey Questionnaire HLS-EU-Q47 conceptual model of HL (Sorensen et al., 2012) or its variation HLS-SF-Q12 (The 12-Item Short Form Health Survey), HL-SDH-Q33 (Health literacy on social determinants of health), HLS-EU-Q86 was used, which differs according to survey questions 12-86, according to the number of respondents from 403 to 10 024, as well as according to the profile of topics of interest in a given research. The analysis indicated the following methods and tests: Confirmatory factor analysis (CFA), Factor analysis, Principle component analysis (PCA), correlations (Pearson and Spearman's), regressions (Multiple linear), Cronbach's and Spearman-Brown methods, Anova, Kaiser-Mayer-Olkin (KMO), Bartlett's test and Chi-squared test. Thus authors chose to use most of the listed methods.

The research was based on HLS-EU-Q47 and while carrying out internal consistency test, it was found out that the alpha coefficient for the 47 items is 0.965 , a $>0.8$, suggesting that the items have high internal consistency.

In the second task of the research the following demographical and socio-economic data on respondents were collected:

Participants. In the study 383 adults (49.9 \% male and $50.1 \%$ female) in age from 18 to 64 (18-19 (27.4\%); 20-29 (35\%); 30-39 (30.5\%); 40-49 (2.6\%); 50-59 (2.6\%); 60-64 (1.8\%)) (M= 2.23， $\mathrm{SD}=1.08$ ) participated.

The education of respondents was from primary or lower than primary to higher (higher (27.4\%); vocational or vocational secondary (35.0\%); general secondary (30.5\%); primary or lower than primary $(7 \%))(M=2.17, \mathrm{SD}=0.913)$.

Gross income per month (EUR) was from $<=200$ EUR to 1500 EUR> $(M=2.39, S D=1.111)$, $<400$ EUR 23.2 \%); 400-700 EUR (35.8\%); 700-1000 EUR (24.0\%); $1000-<1500$ EUR $12.3 \%) ;$ 1500 EUR > (4.7\%).

Principal axis factor analysis with varimax rotation was conducted to access the structure for the 47 items, which identifies 4 factors related to managing health information (access, understand, appraise, and apply information). The assumption of independent sampling was met. Kaiser-Meyer-Olkin Measure (KMO) measure should be greater than 0.70 indicating sufficient items for each factor (Table 1 ).

The assumptions of normality, linear relationships between pairs of variables, and the variables' being correlated at a strong level were checked. For construct validity, confirmatory factor analysis (CFA) was conducted. Four factors were requested, based on the fact that the items were designed to index four aspects of health literacy: access, understand, appraise, and apply information. After rotation, the first 
factor Access accounted for $21 \%$ of the variance, the second factor Understand accounted for $17 \%$, and the third factor Appraise $12 \%$, and the fourth factor Apply for $9 \%$ of the variance.

Table 1

KMO and Bartlett'sTest

\begin{tabular}{|l|c|c|}
\hline \multicolumn{2}{|c|}{ Kaiser-Meyer-Olkin Measure of Sampling Adequacy } & $\mathbf{0 . 9 5 1}$ \\
\hline \multirow{3}{*}{ Barlett'sTest of Sphericity } & Approx. Chi-Square & 20313.743 \\
\cline { 2 - 3 } & $\mathrm{df}$ & 1081 \\
\cline { 2 - 3 } & Sig. & 0.000 \\
\hline
\end{tabular}

Source: author's calculations

In the CFA, we used the comparative fit index (CFI) and the root mean square error of approximation (RMSEA) as the model fit indices. A CFI value $\geq 0.90$ was considered to indicate acceptable model fit. For the RMSEA, a value $<0.05$ represented good fit, and a value $<0.08$ was considered acceptable (Kline, 2010).

The first factor, which seems to index Access, had 24 items, of which 9 was strong loadings on such items: 17) ...find information about how to manage unhealthy behaviour such as smoking, low physical activity and drinking too much? 24) ...judge how reliable health warnings are, such as smoking, low physical activity and drinking too much? 32) ...find information about symptoms of illnesses that concern you? 23) ...understand why you need health screenings? 2) ...find information on treatments of illnesses that concern you? 7) ...understand what to do in a medical emergency? 15) ...call an ambulance in an emergency? 9) ...judge how information from your doctor applies to you? 29) ...decide if you should have a flu vaccination?

The second factors, which seemed to index Understand, had 23 items, of which high loadings on the next five items, where $>0.8: 33$ ) ...find information on treatments of illnesses that concern you? 14) ...follow the instructions on medication? Other items, that are $>0.7: 16)$...follow instructions from your doctor or pharmacist? 25) ...judge when you need to go to a doctor for a check-up? and 18) ...find information on how to manage mental health problems like stress or depression? However, $>0.6$ is for following items: 6) ...understand the leaflets that come with your medicine? 10) ... judge the advantages and disadvantages of different treatment options? 27) ...judge which health screenings you should have? 22) ...understand why you need vaccinations?

The third factors, had 18 items, of which seemed to index Appraise, had high loadings on the next 6 items: $>0.8$ there is 36 ) find out what to do in case of a medical emergency? More than 0.73 ) find out what to do in case of a medical emergency? Items $>0.6$ there are 4) find out where to get professional help when you are ill? And 40) find out what to do in case of a medical emergency?

The fourth factors, had 16 items, of which seemed to index Apply, had high loadings only two next items: $>0.6$ there was 38) ...find information on treatments of illnesses that concern you? and $>0.5$ there was item 41) ...find information about symptoms of illnesses that concern you?

Hierarchical Multiple Regression (in SPSS with Assumption Testing) analysis was performed to determine the role of gender, education, age and gross income per month (EUR) in health literacy predicting (Access, Understand, Appraise and Apply). The assumptions of linearity, normally distributed errors, and uncorrelated errors were checked and met. Further problems were identified, such as a high correlation indicating high correlation among some predictors (age and education $r=0.945$ ) and low multicollinearity 0.105 (tolerances are well over $0.57\left(1-R^{2}\right)$.

When gender was entered alone, it significantly predicted $\mathrm{HL}$ factor Access, $\mathrm{F}(1,830)=0.51$, $\mathrm{p}=0.478$ ), adjusted $\mathrm{R}^{2}=0.01$, however, as indicated by $\mathrm{R}^{2},<1 \%$ of the variance in $\mathrm{HL}$ factor Access. 
When the other variables (gender, age, education and gross income per month) were added, they significantly improved the prediction, $\mathrm{R}^{2}$ change $=0.30$. This indicate that $30 \%$ of the variance in Access was by model. Combination of variables significantly predicted Access, gender $(\beta=-0.006, p=0.849)$, age $(\beta=0.95, \mathrm{p}=0.23)$, education $(\beta=0.100, \mathrm{p}=0.62)$, gross income per month $(\beta=0.223, \mathrm{p}<0.00)$, $\mathrm{F}(4,827)=89.786, \mathrm{p}<.001)$, with all four variables. The partial correlations can be explained as variance that is not explained by any of the other variables, each independent variable is explaining in the outcome variable, therefore age un education can explain the least unique amount of dispersion that age and education explains the least amount of unique variance $5 \%$, but gross income per month reach even $18 \%$. Among male participants, HL was positively associated with age $(\beta=0.19 ; \mathrm{p}=0.003)$, gross income per month $(\beta=0.34 ; \mathrm{p}<.001)$, but was negatively associated with predictor education $(\beta=-0.34$; $\mathrm{p}=0.003)$.

To investigate how $\mathrm{HL}$ factor Understand impacts the predictors, a correlation was identified (age and education $r=0.945)$. When gender was entered alone, it significantly predicted $\mathrm{HL}$ factor Understand, $F(1,830)=1.15, p=0.285)$, adjusted $R^{2}=0.10$, However, as indicated by $R^{2}, 10 \%$ of the variance in $\mathrm{HL}$ factor Understand. When the other variables (gender, education, age and gross income per month) were added, they significantly improved the prediction, $\mathrm{R}^{2}$ change $=0.31$. This indicate that $31 \%$ of the variance in Understand was by model. Combination of variables significantly predicted Understand, gender $(\beta=-0.049, \mathrm{p}=0.093)$, age $(\beta=0.22 \mathrm{p}=0.592)$, education $(\beta=0.235, \mathrm{p}<0.001)$, gross income per month $(\beta=0.207, \mathrm{p}<0.001), \mathrm{F}(4,827)=94.091, \mathrm{p}<.001)$, with all four variables.

To investigate how $\mathrm{HL}$ factor Appraise indicated that when the other variables (gender, age, education and gross income per month) were added, they significantly improved the prediction, $\mathrm{R}^{2}$ change $=0.30$. This indicate that $30 \%$ of the variance in Appraise was by model. Combination of variables significantly predicted Appraise, gender $(\beta=-0.027, \mathrm{p}=0.372)$, age $(\beta=0.37 \mathrm{p}=0.367)$, education $(\beta=0.217$, $\mathrm{p}<0.001)$, gross income per month $(\beta=0.204, \mathrm{p}<0.001), \mathrm{F}(4,827)=94.091, \mathrm{p}<.001)$, with all four variables.

To investigate how HL factor Apply when the other variables (gender, age, education and gross income per month) were added, they significantly improved the prediction, $\mathrm{R}^{2}$ change $=0.30$. This indicate that $30 \%$ of the variance in Apply was by model. Combination of variables significantly predicted Apply, gender $(\beta=-0.033, \mathrm{p}=0.255)$, age $(\beta=0.35, \mathrm{p}=0.383)$, education $(\beta=0.117, \mathrm{p}=0.001)$, gross income per month $(\beta=0.220, \mathrm{p}<0.001), \mathrm{F}(4,827)=94.091, \mathrm{p}<.001)$, with all four variables.

$\mathrm{HL}$ index division (Table 2) according to gender indicate, that out of 192 respondents $47.4 \%$ for women and out from 191 respondents for $46.6 \%$ for men is a "limited health literacy" ("inadequate" + "problematic"). "Excellent" HL evaluation is by $9.8 \%$ higher for women, but "sufficient" HL index is by $5.8 \%$ higher for men. The evaluation 'limited health literacy" was estimated the largest number for respondents from 18-19, 20-29 and 30-39-year groups. In between the different age groups the evaluation "excellent" $\mathrm{HL}$ it was a dominant value in the age group 30-39 and 60> years, that can be explained with higher education. This is due to the fact that respondents with lower education specifically with general secondary education $51.3 \%$ and primary or lower than primary $44.4 \%$ indicate that 'limited health literacy "HL, is more pronounced in groups with lower gross income per month (EUR).

In comparison with other European countries (Fig. 1), if the proportion of people with "limited health literacy" considerably exceeds the average (47.6\%) observed for the overall sample, then for LV008 this amount is by $38.9 \%$ larger.

This research was aimed at a research area that has not been sufficiently analysed in Latvia, i.e., health literacy and health literacy impacting factors and their determination within the inhabitants in the Vidzeme 
statistical region of Latvia. There were 47 questions deployed in $\mathrm{HL}$ matrix that were used in European countries (Sorensen et al., 2015). When confirmatory factor analysis (CFA) was conducted, four factors were determined: (1) Access, included 24 items on availability of information - unhealthy behaviour such as smoking, low physical activity and drinking too much, find information about symptoms of illnesses that concern; (2) Understand, had 23 items information on treatments of illnesses, instructions on medication; (3) Appraise had 18 items found out what to do in case of a medical emergency, find out where to get professional help when you are ill; (4) Apply, where 16 items were determined, about finding of information on treatments of illnesses that concern you, about symptoms of illnesses that concern you. Thus, the second task of the study was fulfilled.

Table 2

HL index division by gender, age, education, and gross income per month

\begin{tabular}{|c|c|c|c|c|c|c|}
\hline & \multirow{2}{*}{ Predictor variables } & \multicolumn{4}{|c|}{ HL index $(\%)$} & \multirow{2}{*}{$\mathbf{N}$} \\
\hline & & $0-25$ & $>25-33$ & $>33-42$ & $>42-50$ & \\
\hline \multirow{2}{*}{ Gender } & Women & 16.6 & 20.8 & 32.9 & 29.7 & 192 \\
\hline & Men & 14.6 & 22.0 & 43.5 & 19.9 & 191 \\
\hline \multirow{6}{*}{ Age } & $18-19$ & 6.7 & 1.9 & 17.1 & 74.3 & 95 \\
\hline & $20-29$ & 14,2 & 24.6 & 57.5 & 3.7 & 134 \\
\hline & $30-39$ & 51.3 & 30.8 & 9.4 & 8.5 & 117 \\
\hline & $40-49$ & 60.0 & 30.0 & 0.0 & 10.0 & 10 \\
\hline & $50-59$ & 50.0 & 40.0 & 10.0 & 0.0 & 10 \\
\hline & $60>$ & 14.4 & 57.1 & 14.3 & 14.3 & 7 \\
\hline \multirow{4}{*}{ Education } & Higher & 6.7 & 1.9 & 17.1 & 74.3 & 105 \\
\hline & Vocational or vocational secondary & 14.2 & 24.6 & 57.5 & 3.7 & 144 \\
\hline & General secondary & 51.3 & 30.8 & 9.4 & 8.5 & 117 \\
\hline & Primary or lower than primary & 44.4 & 40.7 & 7.4 & 7.4 & 27 \\
\hline \multirow{6}{*}{$\begin{array}{l}\text { Gross } \\
\text { income } \\
\text { per month } \\
\text { (EUR) }\end{array}$} & $<=200$ & 52.8 & 28.3 & 18.9 & 0.0 & 53 \\
\hline & $200-400$ & 37.8 & 32.4 & 29.7 & 0.0 & 37 \\
\hline & $>400-700$ & 27.2 & 21.3 & 32.4 & 19.1 & 136 \\
\hline & $>700-1000$ & 9.6 & 13.8 & 29.8 & 46.8 & 94 \\
\hline & $>1000-1500$ & 17.8 & 24.4 & 22.2 & 35.6 & 45 \\
\hline & $>1500$ & 11.1 & 11.1 & 27.8 & 50.0 & 18 \\
\hline
\end{tabular}

Source: author's calculations based on the results of the survey

Source: author's calculations based on Sorensen et al., 2015

Fig. 1. Levels of health literacy index by country and LV008

The identification of HL importance by OECD and the Government of Latvia (IHLA, 2021) increased the interest of authors to research into demographic and social predictors, that could impact $\mathrm{HL}$, for instance, gender, age, education, and gross income per month (EUR), based on Sorensen and other authors (Solar, Iewin, 2010; Sorensen et al., 2012; Bodur, 2017). Taken into account that the calculations of the survey respondents was carried out proportionally to LV008 working age population, therefore the research results were aimed at reaching the given cohort of respondents.

In the research Model 1 it was determined that gender does not significantly impact (only $1 \%$ ) $\mathrm{HL}$ factor Access. However, the Model 2 indicates that, when all health literacy domains were added to regression, 
they improved the prediction of respondents Access to $30 \%$. Predictors age and education has a strong correlation $(r=0.945)$, that similarly to the partial correlation has an impact on factor Access. Education of female respondents is higher than that of men which is indicated by their negatively associated with predictor education. Similar phenomena can be identified within analysis of Understand, Appraise, and Apply. The female respondents are more dominant in categories with higher and general secondary education, but in male respondent groups the dominant categories are vocational or vocational secondary, and primary or lower then primary education. The adjusted R squared value for male factor Access was $27 \%$, Understand $29 \%$, Appraise $27 \%$, and Apply $30 \%$. However, for females the adjusted R squared value factor Access and Understand were $35 \%$, Appraise $34 \%$, and Apply $30 \%$, which is related mainly to the education of women. However, the gross income per month (EUR) of respondents impact all factors, especially for females (gross income per month (EUR)* education, $r=-0.284$; gross income per month $(E U R) *$ age, $r=-0.267)$.

In previous research (Macleod et al., 2017), noted that the respondent HL level is lower especially for people in more senior age, which also affects their abilities to respond to the health problems, thus they have limited Access. Nonetheless in authors research this cohort does not significantly differ from other groups of respondents, but the most important differences are in education. It has been proved that education is the strongest factor what affects health literacy (Martin et al, 2009). It should be taken into account that the education level of respondents only reflects the time spent in education system but not the actual HL skills (De Walt, Pignone, 2005). The authors identified these inconsistencies in between respondents of different education levels and $\mathrm{HL}$ skills. The common tendencies can be observed (Fig. 1), where, compared to evaluation of the HL index by foreign researchers indicated that respondents of LV008 in "limited health literacy" level exceeds that of Bulgaria by $24.4 \%$.

There were limitations in this study. The primary limitation was that the research was conducted on a relatively limited number of inhabitants and bound to a given region - in Vidzeme statistical region LV008. Therefore, before the conclusion were generalized in order to acquire better and more detailed understanding about the health literacy and the related factors, it was recommended to carry out similar research in other regions of Latvia. The second limitation was that, due to fact that a large proportion of respondents were youth, a research should be conducted that has a more proportionate division between different age groups. The third limitation included the division by four demographic and social factors (gender, age, education and gross income per month (EUR)) while excluding other factors, including the cultural factors.

\section{Conclusions and recommendations}

The research allowed to determine four Health Literacy impacting factors within the Vidzeme Statistical Region of Latvia (LV008): Access, Understand, Appraise, and Apply. Study revealed that according to respondents' gender different Health Literacy factor impact was determined. Factors Access and Understand in female respondent population were $35 \%$, Appraise $34 \%$, and Apply $30 \%$, meanwhile for male respondents the factor Access was $27 \%$, Understand 29 \%, Appraise $27 \%$, and Apply 30 \%. Differences were related to the higher education among female respondents, as well as lower impact of the predictor of gross income per month (EUR). It was determined that there are inconsistencies between different levels of education and $\mathrm{HL}$ factors.

European wide research on levels of health literacy index by country revealed that the proportion of responses indicating $\mathrm{HL}$ index "limited health literacy" in Vidzeme statistical region of Latvia exceeded even 
the other largest result by a member state i.e., Bulgaria, where its national HL index for the given answer was by $24.4 \%$ lower than that of Latvia.

in order to gain a better and more detailed understanding of health literacy and related factors, it was recommended to conduct similar researches in other regions of Latvia, in different age cohorts, as well as to include several demographic and social factors.

\section{Bibliography}

1. ABS (Australian Bureau of Statistics) (2008). Health literacy. Australia, 2008: Summary of Findings, Camberra, ACT: ABS.

2. Altin, S.V., Finke, I., Kautz-Freimuth, S., Stock, S. (2014). The Evolution of Health Literacy Assessment Tools: a Systematic Review. BMC Public Health 14, 1207. https://doi.org/10.1186/1471-2458-14-1207

3. Baker, D.W. (2006). The Meaning and the Measure of Health Literacy. Journal of General Internal Medicine, 21, 878-883. DOI: $10.1111 / \mathrm{j} .1525-1497.2006 .00540 . x$

4. Berkman, N. D., Davis, T. C., McCormack, L. (2010). Health Literacy: What is it? Journal of Health Communication, 15: sup2, 9-19. https://doi.org/10.1080/10810730.2010.499985

5. Berkman, N. D., Sheridan, S.L., Donahue, K. E., Halpern, D.J, Crotty, K. (2011). Low Health Literacy and Health Outcomes: an Updated Systematic Review. Annals of Internal Medicine, 2011 Jul 19; 155: 2, 97-107. DOI: $10.7326 / 0003-4819-155-2-201107190-00005$

6. Bodur, A.S., Filiz, E., Kalkan, I. (2017). Factors Affecting Health Literacy in Adults: A Community Based Study in Konya, Turkey. International Journal of Caring Sciences, January- April 2017, 10:1, 100-109.

7. CSB (Central Statistical Bureau of Latvia) (2020). IRG030. Vidējais vecums un iedzīvotāju skaits pēc vecuma un dzimuma statistiskajos reǵionos. (The Average Age and Population Size by Age, Sex in Statistical Regions) Retrieved: https://data.csb.gov.Iv/pxweb/Iv/iedz/iedz_iedzrakst/IRG030.px/table/tableViewLayout1/ Access: 10.02.2021. (in Latvian)

8. Connor, M, Mantwill, S., Schulz, P. J. (2013). Functional Health Literacy in Switzerland: Validation of a German, Italian, and French Health Literacy Test. Patient Education and Counseling, 90:1, 12-17. DOI: 10.1016/j.pec.2012.08.018

9. DeWalt, D. A., \& Pignone, M. P. (2005). Reading is Fundamental: the Relationship Between Literacy and Health. Archives of Internal Medicine, 165: 17, 1943- 44. DOI: 10.1001/archinte.165.17.1943.

10. Freedman, D. A., Bess, K. D., Tucker, H. A., Boyd, D. L., Tuchman, A. M., Wallston, K.A. (2009). Public Health Literacy Defined. American Journal of Preventive Medicine, 36, 446-451. DOI: 10.1016/j.amepre.2009.02.001

11. Guzys, D., Kenny, A., Dickson-Swift, V., Threlkeld, G. (2015). A Critical Review of Population Health Literacy Assessment. BMC Public Health 15, 215. https://doi.org/10.1186/s1288HYPERLINK "https://doi.org/10.1186/s12889-015-1551-6"9-015-1551-6

12. Heijmans, M., Uiters, E., Rose, T., Hofstede, J., Deville, W., van der Heide I., Boshuisen,H., Rademakers, J. (2015). Study on Sound Evidence for a Better Understanding of Health Literacy in the European Union. Final Report, RfS Chafea/2014/health/01. Brussels: European Commission.

13. HLS-EU Consortium. (2012). Comparative Report of Health Literacy in Eight EU Member States. The European Health Literacy Project 2009-2012. Retrieved from: https://www. healthliteracyeurope.net/hls-eu. Access: 28.02.2021.

14. IHLA (International Health Literacy Association) (2021). Global Health Literacy Summit. Retrieved: http://www.ihlasummit2021.org/ Access: 10.02.2021.

15. Kline, R.B. (2010). Principles and Practices of Structural Equation Modeling. 3rd ed. New York: The Guilford Press.

16. Kickbusch, I., Nutbeam, D. (2008). Health Promotion Glossary. Geneva: World Health Organization, 10-12.

17. Kim, S.H. (2009). Health Literacy and Functional Health Status in Korean Older Adults. Journal of Clinical Nursing, 18: 2337-2343

18. MacLeod, S., Musich, S., Gulyas, S., Cheng, Y., Tkatch, R., Cempellin, D., Bhattarai, G.R., Hawkins, K, Yeh, C.S . (2017). The Impact of Inadequate Health Literacy on Patient Satisfaction, Healthcare Utilization, and Expenditures Among Older Adults. Geriatric Nursing, 38:4, 334-341. https://doi.org/10.1016/j.gerinurse.2016.12.003

19. Mancuso, J. M. (2008). Health Literacy: a Concept/dimensional analysis. Nursing and Health Sciences, 10: 3 , 248-255. DOI: $10.1111 / \mathrm{j} .1442-2018.2008 .00394 . x$

20. OECD (2019). OECD Skills Strategy Latvia: Assessment and Recommendations, OECD Skills Studies, Paris: OECD Publishing. https://doi.org/10.1787/74fe3bf8-en.

21. Onose, G., Ancane, G., Capisizu, M. (2017). Doctors' and Older Patients' Health Literacy of Functional Declaine and Frailty. Results from Latvia and Romania. Biophiia 2017:1:21, 21-27. DOI: 10.14813/ibra.2017.21

22. Pelikan, J.M. (2014). Gesundheitskompetenz in der Gesundheitsgesellschaft - eine Herausforderung für Gesundheitswissenschaften, Gesundheitsförderung und die Soziologie" (Health Literacy in the Healthcare system - Challenges to Health Sciences, Health Promotion, and Sociology) In: Holger Penz, Hannes Martinz, Regina Klein, Karl Krajic: Tagungsband Health Literacy als Basiskompetenz (in) der Gesundheitsgesellschaft. Fachhochschule Kärnten 2014, S. 31-36. (in German) 
23. Rasnaca, L., Vibane, K., Nikisins, J. (2017). How Proficiently do we Take Care of our Health? How to Become More Skillful? In: Latvia. Human Development Report 2015/2016. Mastery of Life and Information Literacy. Edited by Baiba Holma. Riga: Advanced Social and Political Research Institute of the University of Latvia. doi.org/10.22364/Ivhdr.2015.2016

24. Rowlands, G., Protheroe, J., Price, H., Gann, B. Raf, I. (2014). Health Literacy: Report from an RCGP-led Health Literacy Workshop. London: Royal College of General Practitioners.

25. Scott, T. L., Gazmararian, J. A., Williams, M. V., Baker, D. W. (2002). Health Literacy and Preventive Health Care Use Among Medicare Enrollees in a Managed Care Organization. Medical Care, 40:5, 395-404. DOI: 10.1097/00005650-200205000-00005

26. Silkane, V., Davidsone, A., Veliverronena, L. (2018). The Role of Health Literacy in Predicting Patient Satification with Health Care. Society. Integration. Education. Proceedings of the International Scientific Conference DOI:10.17770/SIE2018VOL1.3223 Volume VII, May 25th -26th, 2018. 240-250. https://doi.org/10.17770/sie2018voHYPERLINK "https://doi.org/10.17770/sie2018vol1.3223"l1.3223

27. Solar, O., Irwin, A. (2010). A Conceptual Framework for Action on the Social Determinants of Health: Social Determinants of Health Discussion Paper 2. World Health Organization 2010. Geneva: WHO Press.

28. Sorensen K, Van den Broucke, S., Fullam, J, Doyle, G., Pelikan, J., Slonska, Z., Brand, H. (2012). Health Literacy and Public Health: Asystematic Review and Integration of Definitions and Models. BMC Public Health, 12:80. https://doi.org/10.1186/1471-2458-12-80

29. Sorensen, K., Pelikan, J. M. Röthlin, F., Ganahl, K. Slonska, Z. Doyle, G., Fullam, J., Kondilis, B., Agrafiotis, D., Uiters, E., Falcon, M., Mensing, M., Tchamov, K., van den Broucke, S., Brand, H. (2015). Health Literacy in Europe: Comparative Results of the European Health Literacy Survey (HLS-EU). The European Journal of Public Health, 25:6, 1053-1058. DOI: 10.1093/eurpub/ckv043

30. Sorensen, K., Van den Broucke, S., Pelikan, J., Fullam, J., Doyle, G., Slonska, Z., Brand, H. (2013). Measuring Health Literacy in Populations: Illuminating the Design and Development Process of the European Health Literacy Survey Questionnaire (HLS-EU-Q). BMC Public Health, 13:1, 948. DOI:10.1186/1471-2458-13-948

31. Wallace, A. S., Perkhounkova, Y., Bohr, N. L., Chung, S. J. (2016). Readiness for Hospital Discharge, Health Literacy, and Social Living Status. Clinical Nursing Research, 25:5, 494. 